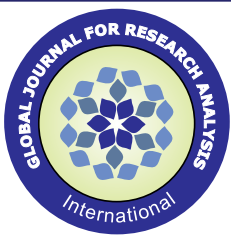

Dr.N.Poonkodi

\section{Dr.B. Grace Mercy Pricilla*}

\title{
ROLE OF SURFACE BRACHYTHERAPY IN PREVENTING RECURRENCE IN RECURRENT EAR KELOID AFTER EXCISION-SINGLE INSTITUTION PROSPECTIVE STUDY
}

ABSTRACT Background:Adjuvant radiation therapy is a recognised option for the treatment of keloid scars. It was

first described by Sequeira in 19091 and is currently considered the most efficacious modality according
to the international advisory panel on scar management. The reported therapeutic response rates are generally in the range of

Assistant professor of Radiation oncology. Madras medical college , Chennai-600003.

Assistant professor of Radiation oncology. Madras medical college , Chennai-600003. ${ }^{*}$ Corresponding Author $67-98 \%$. Following surgical excision of a scar, active blood borne repopulation of fibroblasts occurs; postoperative radiation treatment is thought to prevent recurrence by inducing fibroblastic apoptosis as well as imparting toxicity to endothelial cells. Aim of the study: 1.To confirm post-operative HDR brachytherapy reduce the recurrence in recurrent keloid.

Materials and Methods:All recurrent ear keloids operated at department of plastic surgery, madras medical college were included in the study and brachycatheter inserted during excision and HDR radiotherapy was given early postoperative period. The further fractions are given such that there is $6 \mathrm{hr}$ gap between two fractions. The treatment is given as $3 \mathrm{gy}$ in $4 \#, 4 \mathrm{gy}$ in $3 \#, 6$ gy in 2 \#, 12gy in 1\#. Total dose was 12 gy. Period of study :3 years (2017-2020), conducted in MMC, Chennai.

Primary end point was recurrence. All cases were analysed using standard statistical methods.

Results:Total no cases included were 15. Recurrence found in 1 cases(6\%). Recurrence rate was significantly reduced following post excision HDR brachytherapy $(\mathrm{P}=0.0002)$. Complications encountered are wound dehiscence, hyper/hypopigmentation and thinning of cartilage.

Conclusion: Hereby concluded that recurrence in ear keloids after recurrent ear keloid excision was potentially prevented by HDR surface brachytherapy. It can be useful in other locations for preventing recurrence.

\section{KEYWORDS :}

\section{INTRODUCTION}

Adjuvant radiation therapy is a recognized option for the treatment of keloid scars. (1) It was first described by Sequeira in 19091 and is currently considered the most efficacious modality according to the international advisory panel on scar management.(2) The reported therapeutic response rates are generally in the range of $67-98 \%$.(3)

Keloids are formed due to accelerated proliferation of fibroblasts and an impaired balance between proliferation and apoptosis.(4) Moreover, also due to endothelial dysfunction, mediated via the propagation of the inflammatory response in scar tissue. $(5,6)$ Following surgical excision of a scar, active blood borne repopulation of fibroblasts occurs; postoperative radiation treatment is thought to prevent recurrence by inducing fibroblastic apoptosis as well as imparting toxicity to endothelial cells. $(7,8)$

\section{AIM OF THE STUDY.}

1. To confirm post-operative HDR brachytherapy reduce the recurrence in recurrent keloid.

\section{MATERIALS AND METHODS}

All recurrent ear keloids operated at department of plastic surgery, madras medical college were included in the study and brachycatheter inserted during excision and HDR radiotherapy was given early postoperative period.

\section{METHODS}

After basic workup and proper evaluation at our department regarding the size and extent of lesion, the number of catheters that may be needed, and discussion with the surgeons brachy date is fixed and the patients were taken up for surgical excision of keloid. After the surgery and minimal recovery time patients were immediately shifted to the brachytherapy unit.

- At the brachy unit the dressing is removed and depending on the size of the lesion and the suture, the number of catheters are decided and placed.

- Catheters are fixed in place with custom mold using American clay.

- Guidewire is passed through these catheters and CT images of required area is taken.

- These images are contoured and planned and first fraction of HDR brachy is delivered within 6 hours of surgery.

The further fractions are given such that there is $6 \mathrm{hr}$ gap between two fractions. The treatment is given as 3 gy in $4 \#, 4$ gy in 3\#,6 gy in 2 \#, 12gy in 1\#. Total dose was 12 gy.

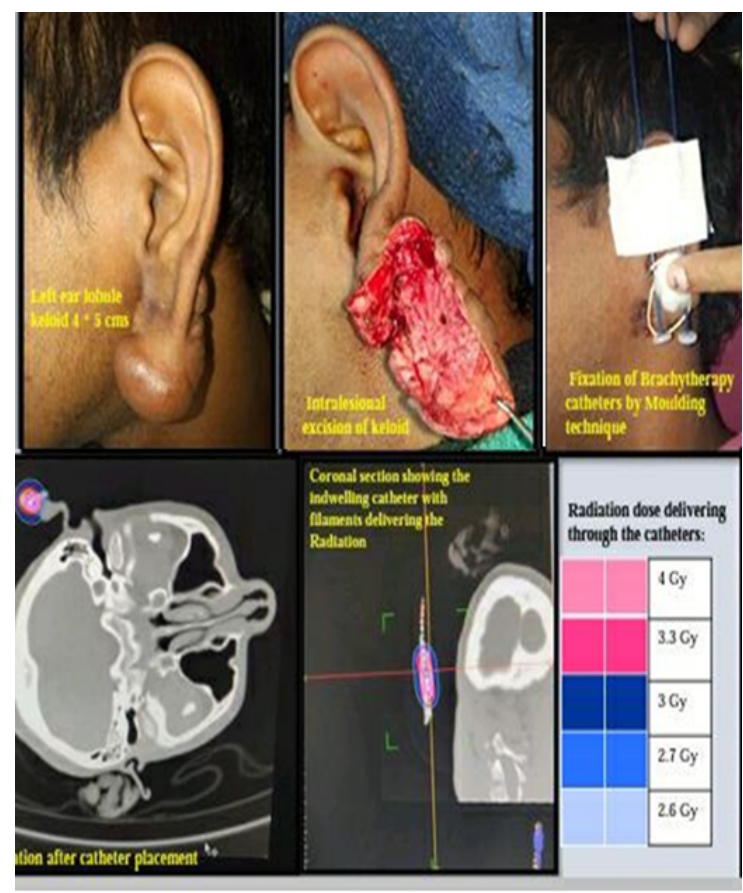

Fig-1. Brachycatheter placement,planning and dosage. 
Period of study : 3 years (2017-2020), conducted in MMC, Chennai.

All cases was followed up monthly for 1 year, 3monthly for 2 nd year and 4 monthly for $3^{\text {rd }}$ year. Primary end point was recurrence. All cases were analysed using standard statistical methods.

\section{RESULTS}

Total no cases included were 15

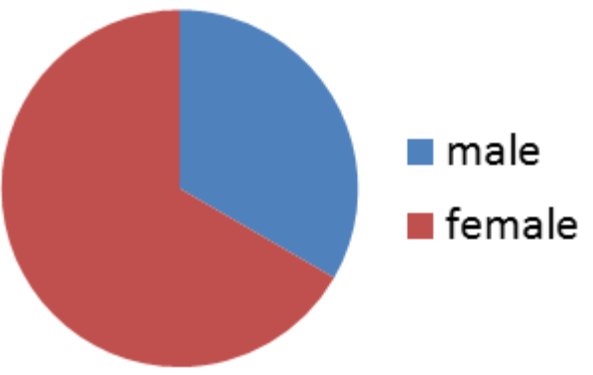

Gender distribution of patients

Etiology of keloid.

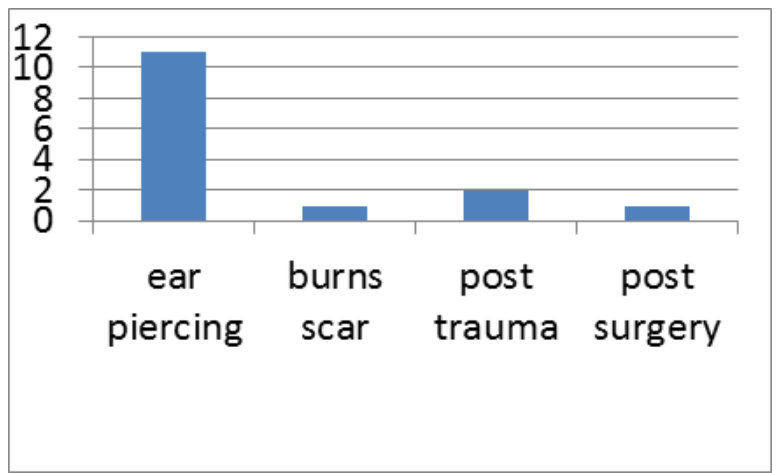

The average age was 30.2 years with a range of $16-67$ years old

The size of the keloid in the group ranged from 2 -18 square centimetres

Table-1Profile of patients and treatment

\begin{tabular}{|c|c|c|c|c|c|c|c|c|c|c|}
\hline & $\begin{array}{c}\text { AGE } \\
\text { (Years) }\end{array}$ & SEX & SIIE & AETIOLOGY & $\begin{array}{l}\text { S12E } \\
\text { (cms) }\end{array}$ & $\begin{array}{c}\text { FII } \\
\text { PATR } \\
\text { ICX } \\
\text { SCAL } \\
E\end{array}$ & $\begin{array}{c}\text { TOT } \\
\text { AL } \\
\text { DOS } \\
\text { E } \\
\text { (Gy) }\end{array}$ & $\begin{array}{c}\text { FrACTIONS } \\
\text { /DOSE }\end{array}$ & $\begin{array}{c}\text { 1ST } \\
\text { DOSE } \\
\text { ADMI } \\
\text { NISTE } \\
\text { RED }\end{array}$ & $\begin{array}{l}\text { TIME OF } \\
\text { COMPLEI } \\
\text { ONOF } \\
\text { BRACHTH } \\
\text { ERRPY }\end{array}$ \\
\hline 1. & 21 & M & LEFT EAR LOBE & EAR PIERCING & $4 \times 3.5$ & IV & 12 & $4 / 3 \mathrm{Gr}$ & 6 HRS & 48HRS \\
\hline 2. & 22 & M & LEFT EAR LOBE & EAR PIERCING & $2 \times 3.5$ & $\mathrm{v}$ & 12 & $4 / 3 \mathrm{Gr}$ & 6 HRS & 48HRS \\
\hline 3. & 34 & $\mathrm{f}$ & $\begin{array}{l}\text { LEFT EAR } \\
\text { MEUCAL RIM }\end{array}$ & EAR PIERCING & $3 \times 4$ & IV & 16 & $4 / 4 \mathrm{Gr}$ & 6 HRS & 48HRS \\
\hline 4. & 16 & $f$ & $\begin{array}{l}\text { DORSUM OF } \\
\text { RIGHTHAND }\end{array}$ & TRAUMA & $4 \times 1$ & IV & 12 & $3 / 4 \mathrm{Gr}$ & 6 HRS & 48HRS \\
\hline 5. & 17 & $\mathrm{f}$ & RIGHTEAR LOBE & EAR PIERCING & $1 \times 2$ & IV & 12 & $2 / 6 \mathrm{Gr}$ & 6 HIS & $24 \mathrm{HRS}$ \\
\hline 6. & 67 & M & $\begin{array}{c}\text { RIGHT } \\
\text { RETROAURICULA } \\
\text { R }\end{array}$ & $\begin{array}{l}\text { POST } \\
\text { PAROTIDECTOMY } \\
\text { SCAR }\end{array}$ & $6 \times 3$ & IV & 12 & $2 / 6 \mathrm{Gr}$ & 6 HRS & 24 HRS \\
\hline 7. & 20 & M & RIGHT FOREARM & POSI TRAUMA & $2 \times 2$ & IV & 12 & $2 / 6 \mathrm{Gr}$ & 6 HRS & 24 HRS \\
\hline 8. & 19 & $\mathrm{f}$ & RIGHTEAR LOBE & EAR PIERCING & $2 \times 2$ & IV & 12 & $2 / 6 \mathrm{Gr}$ & 6 HRS & $24 \mathrm{HRS}$ \\
\hline 9. & 22 & $\mathrm{~F}$ & $\begin{array}{l}\text { RIGHTEAR } \\
\text { MEUCAL RIM }\end{array}$ & POSTBURNS & $4 \times 2$ & IV & 12 & $1 / 12 \mathrm{Gr}$ & $\begin{array}{l}24 \\
\text { HRS }\end{array}$ & $24 \mathrm{HRS}$ \\
\hline 10. & 34 & $f$ & LEFT EAR LOBE & EAR PIERCING & $2 \times 2$ & $\mathrm{v}$ & 12 & $2 / 6 \mathrm{Gr}$ & 6 HRS & $24 \mathrm{HRS}$ \\
\hline 11. & 50 & $\mathrm{f}$ & LEFT EAR LOBE & EAR PIERCING & $2.5 \times 3$ & $\mathrm{v}$ & 12 & $2 / 6 \mathrm{Gr}$ & 6 HRS & 24 HRS \\
\hline 12. & 35 & $\mathrm{f}$ & $\begin{array}{l}\text { RIGHTEAR } \\
\text { HEICAL RIM }\end{array}$ & EAR PIERCING & $3 \times 3$ & v & 12 & $2 / 6 \mathrm{Gr}$ & 6 HRS & $24 \mathrm{HRS}$ \\
\hline 13. & 27 & f & RIGHTEAR LOBE & EAR PIERCING & $2 \times 3.5$ & IV & 12 & $2 / 6 \mathrm{Gr}$ & 6 HRS & $24 \mathrm{HRS}$ \\
\hline 14. & 36 & $\mathrm{f}$ & RIGHTEAR LOBE & EAR PIERCING & $2 \times 2$ & $\mathrm{v}$ & 12 & $2 / 6 \mathrm{Gr}$ & 6 HRS & $24 \mathrm{HRS}$ \\
\hline 15. & 33 & M & LEFT EAR LOBE & EAR PIERCING & $2 \times 3.5$ & $\mathrm{v}$ & 12 & $2 / 6 \mathrm{Gr}$ & 6 HRS & $24 \mathrm{HRS}$ \\
\hline
\end{tabular}

Total no of fractions were given according to availability and and convenience of patients.

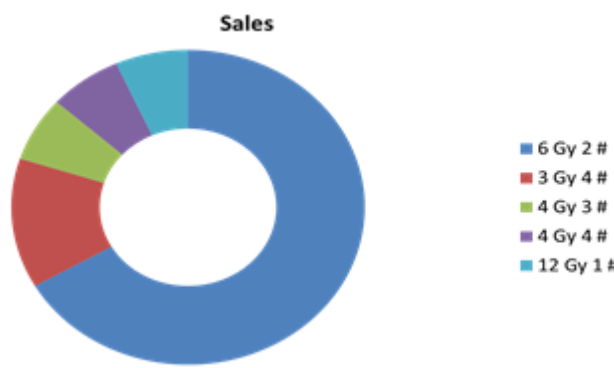

Fig-2. no. of fractions and dose

Most of the cases were given two \#6 gy.

The recurrence rate of keloids in our cohort receiving adjuvant Brachytherapy with surgical excision is $6 \%$ only. The $p$-value analysis for the recurrence rate among the cases shows a value of .000002 . This patient had a post burn keloidal scar in the ear. HDR brachy was delivered as $12 \mathrm{~Gy}$ single fraction within $24 \mathrm{hrs}$ of surgical excision She developed recurrence after 6 months of our therapy seen as a raised and palpable scar over the operated site. This patient was managed with 3 doses of intralesional steroid along with silicone gel sheet. Within 2 months period the scar was flat and skin colour was satisfactory and no further recurrence was encountered.

Table-2. Complications

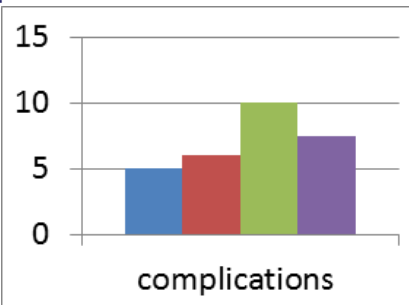

Wound dehiscence $\square$ hyperpigmentation

thinning of ear cartilage

\section{DISCUSSION}

Radiation can be delivered with either external beam radiotherapy (EBRT) or brachytherapy. Brachytherapy appears to have the following comparative advantages $(7,9,10)$.

1. More focused in situ delivery and distribution of radiation to the target area;

2. Less exposure of surrounding healthy skin to radiation; and need for lower dose of radiation to achieve the same therapeutic effect compared to EBRT.

Brachytherapy can be divided into interstitial vs. surface modalities and the former is further subdivided into low dose rate and high dose rate modalities.

In our study we used HDR brachytherapy.

Mechanism of action:

Postoperative radiation treatment is thought to prevent recurrence by inducing fibroblastic apoptosis as well as imparting toxicity to endothelial cells. $(7,8)$.

seven-year prospective study investigating the role of surgery as an adjunct to HDR brachytherapy in 169 scars. In this cohort, 147 patients underwent surgery combined with a total 12 Gy/4 fractions brachytherapy and 22 patients underwent adjuvant brachytherapy only (18 Gy/6 fractions). The median 
follow-up period was 37.3 months (range $=13-85$ months) and the overall recurrence rate (defined as reappearance of the keloid scar in the same location) was $4.7 \%$. Telangiectasia and skin pigmentation changes were seen in twelve and ten patients respectively. The importance of this report was to affirm that the combination of surgery and brachytherapy yields better results compared to isolated modalities(13).

Another case series relates to 17 keloids (previously treated with surgery and external radiation) managed with reexcision and $15 \mathrm{~Gy} / 3$ fractions salvage Ir 192 brachytherapy. At a median follow-up of 26 months, $12 \%$ of keloids showed recurrence(ll).

A retrospective review of 35 patients (54 keloids) employing adjuvant HDR Ir 192 brachytherapy compared the efficacy of the following different regimens (minimum follow-up of 12 months(12)

1. Nine patients with a regimen of $4 / 3 / 3 \mathrm{~Gy}$ (BED of $13.4 \mathrm{~Gy}$ ) showed a recurrence rate of $44 \%$;

2. 38 patients had $6 / 4 / 4$ Gy (BED of 20.8 Gy) with a recurrence rate of $3 \%$;

3. Six patients had $6 / 6 / 6$ Gy and one had a single dose of 16 Gy with no recurrences.

In our study we found the recurrence was $6 \%$. We found that complications were wound dehiscence, hypopigmentation, hyperpigmentation and thining of ear cartilage 5,6,10and 7 respectively. We noted no patients were complicated with telengiectasias.

\section{CONCLUSION.}

Hereby concluded that recurrence in ear keloids after recurrent ear keloid excision was potentially prevented by HDR surface brachytherapy. It can be useful in other locations for preventing recurrence.

Author declares no conflict of interest and no funding was received.

\section{REFERENCES}

1. Sequeira JH. Case illustrating the effects of x-rays on scarkeloid. Proc R Soc Med 1909; 2: 96-98.

2. Mustoe TA Cooter RD, Gold MH et al. International Advisory Panel on Scar Management. International clinical recommendations on scar management. Plast Reconstr Surg 2002; 297: 433-438. Ogawa R, Yoshitatsu S, Yoshida K, et al. Is radiation therapy for

3. keloids acceptable? The risk of radiation-induced carcinogenesis. Plast Reconstr Surg 2009; 124: 1196-1201.

4. Luo S, Benathan M, Raffoul W, et al. Abnormal balance between proliferation and apoptotic cell death in fibroblasts derived from keloid lesions. Plast Reconstr Surg 2001;107: 87-96.

5. Huang C, Liu L, You Z, et al. Endothelial dysfunction and mechanobiology in pathological cutaneous scarring: lessons learned from soft tissue fibrosis. Br J Dermatol 2017. DOI:10.1111/bjd.15576.

6. Ogawa R. Keloid and hypertrophic scars are the result of chronic inflammation in the reticular dermis. Int J Mol Sci 2017; 18: E606.

7. Dinh $Q$, Veness $M$ and Richards $S$. Role of adjuvant radiotherapy in recurrent earlobe keloids. Aust J Dermatol 2004;45: 162.

8. Chaudhry MR, Akhtar S, Duvalsaint F, et al. Earlobe keloids, surgical excision followed by radiation therapy: A 10-year experience. Ear Nose Throat J 1994; 73: 779-781

9. Escarmant P, Zimmermann S, Amar A, et al. The treatment of 783 keloid scars by iridium 192 interstitial irradiation after surgical excision. Int J Radiat Oncol Biol Phys 1993: 26: 245-251.

10. 15. Van Leeuwen MCE, Stockmans SC, Bulstra AEJ, et al. Surgical excision with adjuvant irradiation for treatment of keloid scars: A systematic review. PRS 2015; 3: e440.

11. Garg MK, Weiss P, Sharma AK, et al. Adjuvant high dose rate brachytherapy (Ir-192) in the management of keloids, which have recurred after surgical excision and external radiation. Radiother Oncol 2004; 73: 233-236.

12. Veen RE and Kal HB. Postoperative high dose rate brachytherapy in the prevention of keloids. Int J Radiat Oncol Biol Phys2007; 69: 1205-1208.

13. Nicolettis $C$ and Cassagne D. L'irridiation interstitielle parl'iridium 192 dans la prevention des recidives après excision chirurgicalle des cicatrices cheloidiennes. Ann Chir Plast 1967; 12: 237-242. 